\title{
The Deep Integration of Modern Sports and Media Promoting Sound Development
}

\author{
Xueyan Zhang* \\ School of Communication and Arts, Shanghai University of Sport, Shanghai, China \\ ${ }^{*}$ Corresponding author. Email: dchzhang2007@163.com
}

\begin{abstract}
In modern society, the sports and media both have the common market and are more and more closely combined. The sports and media influence and depend on each other, thus giving birth to the sports media industry. Through the analysis of the functional characteristics and internal relations between modern sports and media, this paper discusses the essential of sports and media, the effect of media on sports development and the positive influence of sports on media. It is believed that strengthening mutual symbiosis plays a positive role in the deep integration of sports and media, promoting the benign development of sports media industry.
\end{abstract}

Keywords: Sports, Media, Deep integration, Sound development.

\section{INTRODUCTION}

With the development of social economy, sports have gradually developed into sports industry. The sports industry cannot be separated from communication. The sustainable development of sports industry requires a large number of audiences. The media combine audiences with sports. Media play an indispensable role in the development of sports industry. Meanwhile, sports provide more opportunities for the media. With the rapid development of international sports exchanges, the media market goes to the world, making the content of the media more professional and international. Sports and communication are very familiar in the public. They influence each other and co-exist, promoting the prosperity and development of sports media industry.

Wang Lefei et al [1] stated that the relationship between sports culture and media was analyzed, further suggesting the evolution of sports culture. The increasingly developed communication plays a important role in the development of sports culture. Bi Xuemei [2] studied the sports participation and relationship. They made a beneficial attempt to expand the existing theoretical framework of sports communication from the perspective of communication and sociology. Tan Zhengdian et al [3] analyzed the reasons for the combination of media and sports from the perspective of sociology and culture. The relationship between their mutual influence and promotion was elaborated. It was pointed out that media and sports relied on each other, forming a symbiotic effect. Zhang Mengqian [4] concluded the media operation mode of sports events using the theory of communication. The basic countermeasures were provided for the sports industry in China transformation period. Chen Wenjing [5] elaborated the current situation of sports journalism and communication in China. All kinds of information in sports and sports-related fields, methods, behaviors and phenomena were analyzed in the communication process. The development trend was put forward. $\mathrm{Xu}$ Ligang clarified that media and sports have beyond the simple relationship between reports and reported objects, forming a situation of mutual promotion and development [6]. Under the background of industrialization, the cooperation between sports and media is inevitable and their outlook will be bright.

\section{FUNCTIONAL CHARACTERISTICS OF MODERN SPORTS AND MEDIA}

Modern sports are divided into mass and professional sports, whose elements include culture, activities, education, competitions, facilities, organizations, science and technology. The essence of sports is to take physical exercise, promoting the comprehensive development. Modern sports are the complex social and cultural phenomenon, which uses body and intellectual activities as the basic means. 
According to the laws of body growth, skill formation and function improvement, the physical quality and education level are improved to realize the overall development. The life style and quality are improved, which is a conscious, purposeful, organized social activity.

The function of sports is divided into society and individual. The social function of sports includes economy, policy, culture and education, while the individual function of it includes physical fitness, mental health, recreation and communication.

Communication is the purposeful information transmission between two independent systems by media or channels. The function of media is the ability and impact of communication on people and society and communication needs certain media to realize. The media have the organizational functions including notification, expression, explanation and instruction. The social functions of it contain politics, economy and education. Additionally, the functions of media also have communication and entertainment. The functions of media and sports overlap, which is one of reasons for their close connection and cooperation. Only by the mutual promotion, can sports and media achieve sound development.

\section{THE PROMOTION EFFECT OF MEDIA ON SPORTS DEVELOPMENT}

\subsection{The Publicity of Media to Sports}

The media have the strong technical advantages and technological means, which has become an important way to publicize the modern sports industry. The Olympic spirit has been influenced the people generation after generation, to a large extent due to the publicity of media to sports. Before the opening ceremony of Beijing Olympic Game, the audiences all over the world learned about it through the media. The propaganda languages and the theme songs spread all over the country. As a global and international sports event, the Olympic Games need to attract audiences from all over the world. The publicity of the media is crucial and the advertising effect of news, reports, programs, websites and media is indispensable. The fitness, entertainment, education, economy, politics and communication of sports are strengthened by the publicity and package of media [7].

\subsection{The Media Accelerating the Commercialization of Sports}

The sports industry is mainly divided into competition performance and fitness entertainment. The competition performance is closely related to communication. The wonderful processes and pictures of sports are showed to the public, making the audiences interested in it. The recreation of sports is also bound to arouse the interest of the media. This is because communication also can entertain the public. The emergence of sports stars is a key factor for the media to attach importance to sports. It will inevitably attract wide attention and bring a higher topic or attention.

The sports industry and industrialized media both take economic benefits as the priority. The close connection between the advertising market and the media helps to turn certain elements of sports events into commercial brands. Sports are commercialized by media, while the media provide the possibility for the commercialized sports. The formation and development of the sports market are promoted by media and the sports can achieve its economic function through the media. Tickets for sports events on sale are closely related to the media propaganda. In a word, media has laid a certain foundation for commercializing the sports industry.

\subsection{Consensus Supervision of Media}

The sports competitions attach attention to fairness. While reporting sports events in a real, objective, accurate and timely manner, the media can supervise all aspects of them through consensus. In modern society, many large-scale sports events are broadcast live or rebroadcast by the media. Once the sports events are broadcast, all kinds of news, reports and programs will be presented to the audiences through the media. The media can magnify the details of the sports field and every detail can be clearly exposed. The timeliness of news and the immediacy of transmission are so fast that the audiences on the scene, millions of viewers watching TV and countless fans can see them in the first time. So the fair competition of sports events, the standard of referees, ethics, the organization and management are enhanced. The supervision of the media makes sports competitions more fair, just and open, promoting the healthy development of the modern sports industry.

\subsection{The Media Promoting the Physical Education}

The education is another reason to combine sports with the media. The media is conducive to understanding, loving and knowing the movements and cultures, advocating national fitness. The TV, as the public platform, also can popularize the sports. The audiences not only can pay attention to sports stars and events, but also know the culture, knowledge and rules of events from many countries. More and more people are familiar with sports and the sports knowledge of the public are enriched, making more people participated in activities. The media enables the education of sports to be fully developed [8]. 


\section{THE POSITIVE EFFECT OF SPORTS ON MEDIA}

\subsection{Sports Improving Attention and Influence of Media Industry}

The sports convey the positive energy to make progress. The sports symbolize the vitality, youth and sunshine. Transmitting the sports will make communication more vibrant and attractive. Many sports events make the transmission exciting and fascinating. The sports have improved the overall level of the media. The important sports events are organized and planned, collected and edited carefully to seek for fresh and unique perspectives to report them. The news and information reported can stimulate the interest of the audiences. The organization, coordination and operation of the media have greatly improved by a number of news reports. The sports itself is border less and highly appreciated. The sports attract the attention of people from all countries, nationalities, levels and fields with its powerful charm. It will have a huge social influence.

\subsection{Sports Promoting the Rapid Development of the Media Industry}

The sports enrich the content of communication and bring benefits to the media, so the commercialization and market of the media industry are promoted by the sports. The sports provide a broad space for the communication. The media can obtain substantial benefits from broadcasting high-profile, large-scale and international events. The media industry relying on the sports can achieve great benefits. The sports provide a fast-growing business opportunity for the media industry. The deep integration between sports and media will greatly promote the rapid development of media, accelerating the market and commercialization of the media industry [9].

\subsection{Sports Making the Media Industry International}

The international exchanges have gradually expanded. The scale and level of sports has become an important indicator to measure the progress of nation and society. The sports have become an important means of diplomatic and cultural exchanges. The sports are the social culture and educational activity with wide influence. It plays a unique role in dealing with international relations. The sports can enhance national prestige, serving diplomacy and enhancing national unity. The international sports exchanges can promote mutual understanding and trust between countries and ethnic groups, promoting the peace and development of human society. The media with the functions of politics and communication are closely related to sports. With increasing the modern international events, the media of sports are developing towards the more international direction [10].

\subsection{Sports Making the Media Industry More Specialized}

The sports can promote the specialization of media. The media found the business opportunity of sports, which gave rise to the professional channels, programs, newspapers and websites. There is a special sports channel, CCTV-5 in China. The newspapers include China Sports, Sports Morning, Football and Titan Sports Weekly. There are newspapers abroad such as France Football, La Gazzetta Dello Sports, Sports Illustrated. In addition, as a part of the entertainment industry, domestic and foreign programs can be found everywhere. All kinds of games and competitions with sports elements and real sports show emerge in an endless stream. As a result, media management develops towards specialization and sports makes the specialization of media become more obvious.

\subsection{Sports Promoting the Innovation of Media}

Sports help to improve the technology of communication. With the rapid development of the science and technology, there are many sports that need high technology shooting. In order to make the pictures smooth and stable during marathon, battery camera cars and shock absorbers are used. The remote underwater positioning cameras are used to track athletes in the water. The digital technology, intelligent network are used to adapt to the modernization and scientization. In addition, some events are presented to the audiences by new media. Therefore, the rapid development of sports have a great effect on the innovation of communication technology.

\section{CONCLUSIONS}

Sports and media have a high degree of functional compatibility, and there is an internal relationship between them. Parts of function of modern sports need to be realized through the media. Meanwhile, the media can enrich their content with sports. Sports and communication share a common market and they are mutually beneficial and win-win. The mutual symbiosis and deep integration between sports and media will surely produce huge economic and positive benefits.

\section{REFERENCES}

[1] Wang Lefei, Cheng Min.2017.The relation between sports culture and media. Chinese and Foreign Entrepreneurs, (15):246.

[2] Bi Xuemei.2015.Sports relation: the essence of sports participation, communication relation and 
interactive connotation. Journal of Beijing University of Physical Education, 38(12):10-14.

[3] Tan Zhengdian, Xiao Mouwen.2000.The symbiotic effect of sports and media. Journal of Guangzhou Physical Education institute, 20(3):38-41.

[4] Zhang Mengqian.2017. Research on the relationship between sports industry and news media in China. Sports Space and Time, (7):108.

[5] Chen Wenjing.2012.Development status of sports journalism and communication.Sports World (Academic edition), (6):88-89.

[6] Xu Ligang. 2004. Sports and media matching in heaven. Journalist, (6):16-19.
[7] Li Liqun. 2017 Research on the relationship between sports and communication. Contemporary Sports Technology, 7(2):206-207.

[8] Liu Weijun.2004. Research on the interaction between professional sports and mass media in China. Beijing Sports University,

[9] Li Liqun.2017.Research on the relationship between sports and communication.Stationery and Technology, 21(21):23-24.

[10] Ji Weilong.2011. Analysis of relationship between sports media and events. Motion, (11):143-144. 